\title{
$2-2013$
}

\section{A Novel Report of Hatching Plasticity in the Phylum Echinodermata}

A Frances Armstrong College of William and Mary

Holly N. Blackburn

College of William and Mary

Jonathan D. Allen

College of William \& Mary, jdallen@wm.edu

Follow this and additional works at: https://scholarworks.wm.edu/aspubs

Part of the Marine Biology Commons

\section{Recommended Citation}

Armstrong, A Frances; Blackburn, Holly N.; and Allen, Jonathan D., A Novel Report of Hatching Plasticity in the Phylum Echinodermata (2013). American Naturalist, 181(2), 264-272.

$10.1086 / 668829$

This Article is brought to you for free and open access by the Arts and Sciences at W\&M ScholarWorks. It has been accepted for inclusion in Arts \& Sciences Articles by an authorized administrator of W\&M ScholarWorks. For more information, please contact scholarworks@wm.edu. 
Natural History Note

\title{
A Novel Report of Hatching Plasticity in the Phylum Echinodermata
}

\author{
A. Frances Armstrong, ${ }^{\star}$ Holly N. Blackburn, ${ }^{\star}$ and Jonathan D. Allen ${ }^{\dagger}$ \\ Biology Department, College of William and Mary, Williamsburg, Virginia 23187 \\ Submitted May 21, 2012; Accepted September 11, 2012; Electronically published December 31, 2012 \\ Dryad data: http://dx.doi.org/10.5061/dryad.5cp70.
}

\begin{abstract}
Hatching plasticity occurs in response to a wide range of stimuli across many animal taxa, including annelids, arthropods, mollusks, and chordates. Despite the prominence of echinoderms in developmental biology and more than 100 years of detailed examination of their development under a variety of conditions, environmentally cued hatching plasticity has never been reported in the phylum Echinodermata. Here we report plasticity in the timing and stage of hatching of embryos of the sand dollar Echinarachnius parma in response to reductions in salinity. Embryos of E. parma increased their time to hatching more than twofold in response to ecologically relevant salinity reductions, while maintaining an otherwise normal developmental schedule. Embryos that experienced the greatest delay in hatching time emerged from the fertilization envelope as fourarm pluteus larvae rather than hatching as blastulae or early gastrulae. Salinity manipulations across multiple male-female pairs indicated high variability in hatching time both within and among clutches, suggesting significant intraspecific variation in developmental responses to salinity.
\end{abstract}

Keywords: echinoderms, hatching, plasticity, development.

\section{Introduction}

Hatching plasticity is a widespread phenomenon in which the environment induces a change in the duration of the embryonic period or the stage at which hatching occurs (Warkentin 2011). Hatching plasticity is frequently adaptive in nature and can provide embryos with a short-term means for avoiding a detrimental environment (e.g., predation; Vonesh and Bolker 2005). Environmentally cued hatching can be exhibited as either early onset of hatching or delay of hatching. For example, spitting spiders, Scytodes pallida, are egg brooders that are prey for the jumping spider, Portia labiata. In response to chemical cues from jumping spiders, adult female $S$. pallida induce early-onset

\footnotetext{
* These authors contributed equally to this note.

${ }^{\dagger}$ Corresponding author; e-mail: jdallen@wm.edu.

Am. Nat. 2013. Vol. 181, pp. 264-272. (C) 2012 by The University of Chicago. 0003-0147/2013/18102-53860\$15.00. All rights reserved.

DOI: $10.1086 / 668829$
}

hatching in their embryos to increase survival rates of both parent and offspring (Li 2002; Li and Jackson 2003, 2005). Delay of hatching occurs in the California grunion, Leuresthes tenuis, an intertidal fish whose embryos delay hatching for up to 1 month until the flood tide returns, an adaptive response that ensures that hatching occurs during immersion in water (Martin 1999; Martin et al. 2011).

Among deuterostomes, only vertebrate representatives of the phylum Chordata have been shown to exhibit hatching plasticity (Warkentin 2011). Perhaps the best known studies come from amphibians (Warkentin 2005, 2011). Embryos of the red-eyed tree frog, Agalychnis callidryas, hatch early in response to physical disturbance of clutches by egg-eating snakes (Warkentin 1995). Similarly, in response to pathogenic water molds, the embryos of the American toad, Bufo americanus, hatch early to avoid infection (Touchon et al. 2006). In contrast, embryos of the streamside salamander, Ambystoma barbouri, delay hatching in the presence of chemical cues from flatworms, which selectively prey on larvae rather than on eggs (Sih and Moore 1993). Despite the apparent prevalence of hatching plasticity in vertebrates, this phenomenon has not been described in nonvertebrate chordates (i.e., Cephalochordata and Urochordata) or other deuterostome phyla (i.e., Hemichordata and Echinodermata; Warkentin 2011).

Like the offspring of other marine invertebrates, echinoderm and hemichordate eggs and embryos frequently develop within a variable aquatic environment where there are unique selective pressures on the evolution of life histories (Strathmann 1990). Among all marine invertebrate phyla, examples of hatching plasticity are rare, but they do exist. For example, embryos of the polychaete Boccardia proboscidea rely on the female to rip open egg capsules; in cold temperatures, females will delay liberation of their embryos and nearly double the embryonic period, yet the stage at which embryos hatch is earlier than that at warm temperatures (Oyarzun and Strathmann 2011). 
In echinoderms, previous studies have reported alterations in hatching time as a response to temperature and salinity changes (Roller and Stickle 1985, 1994; Stickle and Diehl 1987). Warmer temperatures generally yield faster development, and decreased salinity tends to slow development in some species of sea urchins (Roller and Stickle $1985,1993)$. However, none of these environmental fluctuations changed the stage at which embryos hatched. Across echinoderms, hatching stage is reported to be relatively invariant, with hatching occurring at the blastula stage in echinoids and no later than the gastrula stage in any echinoderm with free-swimming larvae (Staver and Strathmann 2002). The onset of swimming at the blastula stage is thought to be an adaptive mechanism for avoiding both benthic and pelagic predators (McDonald 2004, 2012). Despite these and other studies on form and function at hatching in echinoderms, no studies have reported environmentally induced plasticity of the hatching stage in this phylum.

Here, we describe hatching-stage plasticity in the sand dollar Echinarachnius parma, the first report of its kind among nonvertebrate deuterostomes and one of only a handful among all marine invertebrate phyla. In the course of studying the effects of salinity fluctuations on fertilization and early development in E. parma (Allen and Pechenik 2010), we observed that changes in salinity frequently lead to unusual developmental patterns, including the production of twins (J. D. Allen and A. F. Armstrong, unpublished manuscript) and significant delays of hatching. Nearshore, shallow subtidal, and intertidal habitats have rapid and frequent changes in dissolved oxygen, salinity, and temperature due to tides, weather, and freshwater input (Stickle and Denoux 1976; Breitburg 1990; Sanford 2002; Kaplan et al. 2003). It would therefore not be surprising to find potentially adaptive developmental responses to environmental fluctuations among organisms that live in these variable habitats. After our unexpected initial observations, we conducted a set of experiments to test the effects of temperature and salinity on hatching timing and stage in E. parma, a species that experiences wide variation in temperature and salinity throughout the course of the spawning season.

\section{Material and Methods}

\section{Preliminary Observations}

Adult sand dollars were collected from the intertidal area of Cedar Beach on Orr's Island, Maine $\left(43^{\circ} 45^{\prime} \mathrm{N}, 69^{\circ} 58^{\prime} \mathrm{W}\right)$ in June and July of 2010. Spawning was induced by intracoelomic injection of $1 \mathrm{~mL}$ of $0.5 \mathrm{M} \mathrm{KCl}$, and after eggs were rinsed in $0.45-\mu \mathrm{m}$ filtered seawater (FSW), gametes were combined in bowls containing $100 \mathrm{~mL}$ of FSW. With heated water baths and a flow-through seawater system, three different temperature treatments were created: ambient $\left(17^{\circ}-18^{\circ} \mathrm{C}\right), 19^{\circ}$, and $21^{\circ} \mathrm{C}$. Embryos were reared in glass bowls of 26-psu (practical salinity units) FSW. After $8 \mathrm{~h}$ of development, but before hatching, embryos were transferred from bowls into six-well plates containing 10 $\mathrm{mL}$ of 30-psu FSW in order to track consequences of temperature and salinity stress during embryonic development. Three separate trials were run during the summer of 2010 , each on separate days with unique male-female pairs.

\section{Adult Collection and Spawning Methods}

After the unexpected observations of 2010, we conducted detailed studies of the effects of temperature and salinity on hatching in Echinarachnius parma. In the fall of 2011, adult E. parma were collected from St. Helena Island, Stonington, Maine $\left(44^{\circ} 07.58^{\prime} \mathrm{N}, 68^{\circ} 38.43^{\prime} \mathrm{W}\right)$ and shipped overnight to the College of William and Mary in Williamsburg, Virginia, where they were maintained in recirculating aquaria at $12^{\circ} \mathrm{C}$ and 32 psu. Spawning was induced by intracoelomic injection of $1 \mathrm{~mL}$ of $0.5 \mathrm{M} \mathrm{KCl}$. To collect gametes, adults were inverted over glass beakers containing 32-psu artificial seawater (ASW; Instant Ocean, Aquarium Systems, Mentor, OH). In each trial, gametes from a distinct male-female pair were combined. Animals were not reused. Eggs were rinsed with 32-psu ASW before fertilization.

\section{Experimental Setup}

Glass bowls containing $100 \mathrm{~mL}$ of ASW were placed in water baths to maintain temperatures of $18^{\circ}, 20^{\circ}$, or $22^{\circ} \mathrm{C}$. Depending on the number of eggs released, $2-3 \mathrm{~mL}$ of egg suspension were pipetted into each bowl, for a final density of approximately 50 eggs $\mathrm{mL}^{-1}$. Eggs were allowed 5-10 $\mathrm{min}$ to acclimate to the salinity/temperature treatment before $50 \mu \mathrm{L}$ of dilute sperm were added. After at least $30 \mathrm{~min}$, fertilization was scored according to the presence of a fertilization envelope. Trial 1 consisted of three replicate bowls of 26- and 32-psu salinity placed in each of the three temperature treatments. Trials 2 and 3 consisted of four replicate bowls of 26-, 29-, and 32-psu salinity, each in a single temperature treatment of $18^{\circ} \mathrm{C}$. The single temperature treatment of $18^{\circ} \mathrm{C}$ was chosen because the delay of hatching was greatest at this temperature in trial 1 and because this temperature is also the closest to natural spawning temperatures for E. parma in Maine (J. D. Allen, personal observation). 


\section{Data Collection and Analysis}

To determine the percentage of embryos that had hatched at a given time, three subsamples of 50 embryos were examined from each bowl. Bowls were sampled in a random order at each time point. The water in the bowl was gently swirled with a disposable pipette to ensure that unhatched embryos on the bottom of the bowl and hatched swimming embryos were evenly distributed. Samples were transported gently to reduce the likelihood of mechanically induced hatching. Each sample was then placed under a dissecting microscope and scored for the number of hatched and unhatched embryos. Each sample was discarded after being scored for hatching to ensure that any cues from stressed embryos had no effect on the embryos remaining in the original treatment bowl.

During trial 3, one additional subsample was taken from each bowl to compare larval sizes at $28 \mathrm{~h}$ after fertilization. Length and width were measured in 10 hatched and 10 unhatched embryos from each replicate bowl. Measurements were taken at $100 \times$ magnification under a compound microscope fitted with an ocular micrometer.

We used the binomial logistic regression procedure in SPSS (ver. 18.0) in order to analyze the effects of age, temperature, salinity, and their interactions on the occurrence of hatching. The mixed-models procedure in SPSS was used to analyze the fixed effects of salinity, hatching status, and their interaction on embryo size. Replicate bowls were modeled as random effects. Post hoc tests with a Bonferroni correction were employed to distinguish between the three salinity treatments when significant main effects of salinity were detected.

\section{Results}

\section{Preliminary Observations}

In the three preliminary trials in 2010, delay of hatching was seen to some extent in all trials. A delay of up to 32 $\mathrm{h}$ after fertilization was seen in approximately $50 \%$ of embryos. Whereas Echinarachnius parma larvae normally hatch at the blastula or early gastrula stage, we frequently observed the development of skeletal rods and arms characteristic of the pluteus larval stage before hatching (fig. 1). However, since this phenomenon was unexpected, and not the subject of the original study, we did not closely monitor embryos for precise hatching times.

\section{Effects of Salinity and Temperature on Hatching Time}

In 2011, trial 1 examined delay of hatching at various temperature and salinity combinations (fig. $2 A$ ). Along with age, salinity ( 26 or $32 \mathrm{psu}$ ) and temperature treatments $\left(18^{\circ}, 20^{\circ}\right.$, or $\left.22^{\circ} \mathrm{C}\right)$ and their interactions were sig-

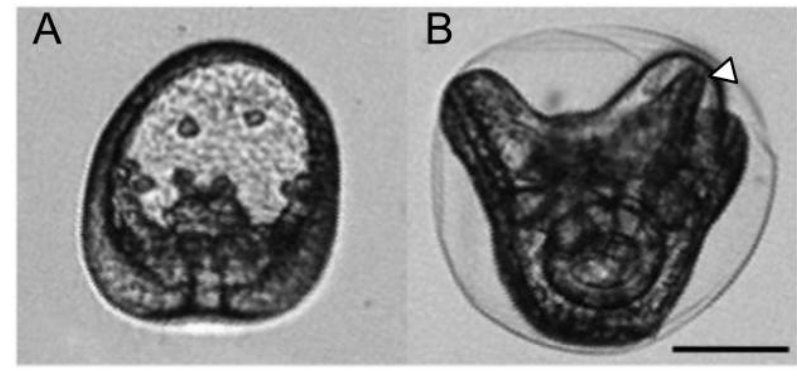

Figure 1: Hatched early gastrula at $22 \mathrm{~h}$ after fertilization $(A)$ and four-arm pluteus larva delaying hatching at $37 \mathrm{~h}$ after fertilization $(B)$. Arrowhead points to left posterodorsal arm. Note the retention of the fertilization envelope in $B$. Both offspring were reared at $18^{\circ} \mathrm{C}$ and 32 psu. Scale bar $=100 \mu \mathrm{m}$.

nificant predictors of hatching status (fig. $2 A$; table 1). In particular, embryos in the $18^{\circ} \mathrm{C}$ treatments exposed to 26 psu ASW exhibited significantly delayed hatching relative to those exposed to 32 psu (fig. $2 A$ ). A Hosmer-Lemeshow test of the logistic regression model we used suggested a significant lack of fit to the data $(P<.001)$. However, since the Hosmer-Lemeshow statistic is known to yield significant lack of fit under conditions of large sample sizes (as is the case here, with 40,500 embryos scored for hatching status) and since our model accurately predicted hatching status in $91 \%$ of cases, we continued to use this model for our analysis (Kramer and Zimmerman 2007). As expected, both age and temperature had strong effects on hatching status, but salinity also had a significant effect on the likelihood of hatching at a given age: for every unit increase in salinity, the odds of hatching increased by a factor of 15.525 (table 1).

Trials 2 and 3 examined delay of hatching across salinity treatments of 26,29 , and 32 psu (fig. $2 B, 2 C$ ). As in trial 1 , the 26-psu treatment exhibited the greatest delay in hatching. The logistic regression model used to analyze trial 2 again had a significant lack of fit, according to a Hosmer-Lemeshow test $(P<.001)$, yet it predicted hatching status with $94 \%$ accuracy. Age, salinity, and their interaction were found to be significant predictors of hatching status (table 1). Similarly, the logistic regression model created from trial 3 exhibited a significant lack of fit to the data (Hosmer-Lemeshow test; $P<.001$ ) yet predicted hatching status with $85 \%$ accuracy. As in trial 2 , the factors of age, salinity, and their interaction were found to be significant predictors of hatching. In trial 3 , unlike the other trials, treatments never reached $100 \%$ hatching. Embryo hatching was followed closely for $88 \mathrm{~h}$ after fertilization. After this point, embryos were assessed periodically until 5 days after fertilization, by which time unhatched 

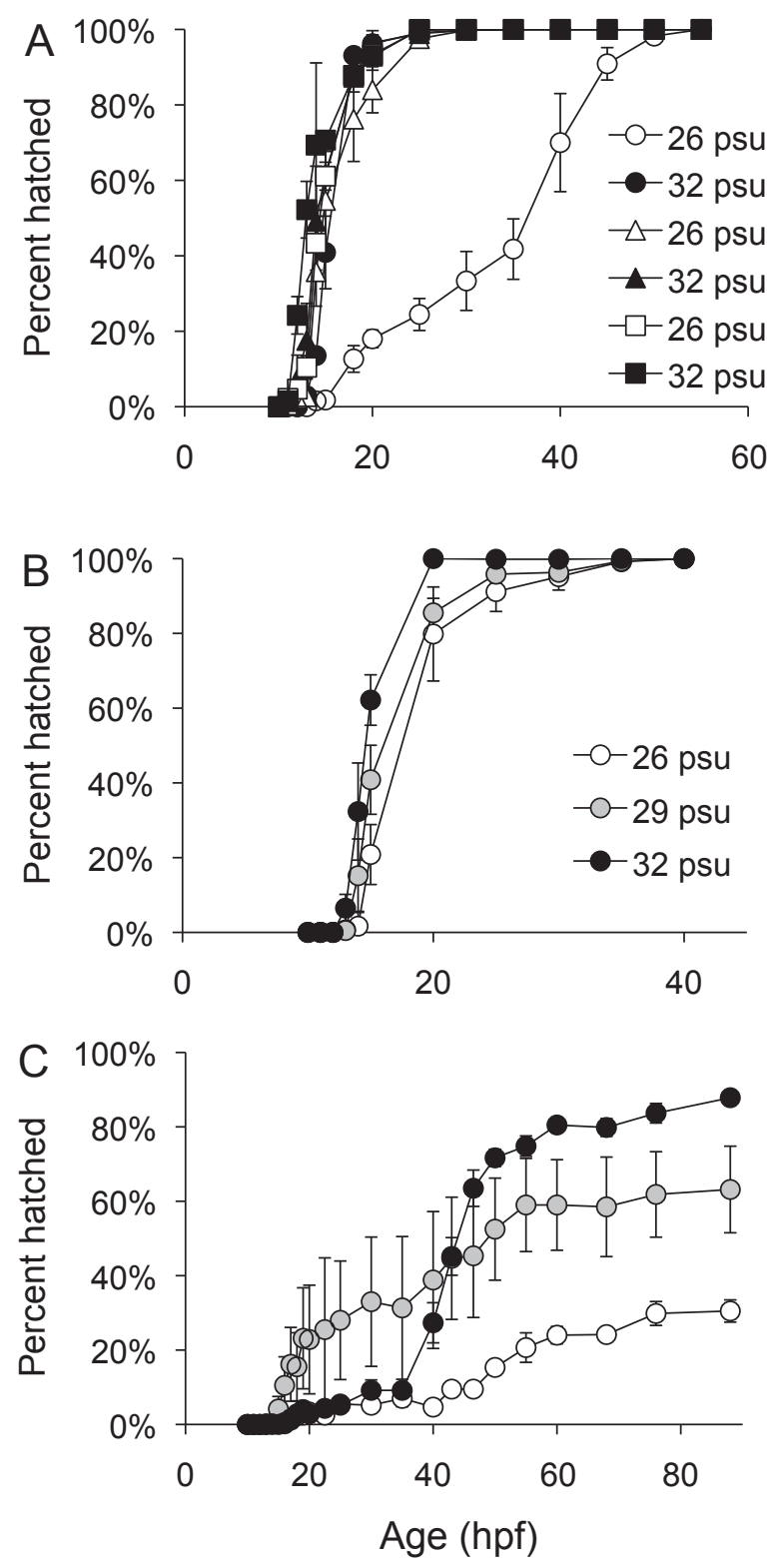

Figure 2: Percent hatching of Echinarachnius parma embryos during salinity and temperature treatments. Each panel represents a single trial using an independent male-female pair. Trial $1(A)$ assessed hatching under combinations of two salinity and three temperature treatments. Circles, triangles, and squares represent $18^{\circ}, 20^{\circ}$, and $22^{\circ} \mathrm{C}$ treatments, respectively. Trials $2(B)$ and $3(C)$ tested three salinities at $18^{\circ} \mathrm{C}$. In all trials, age, salinity, temperature, and their interactions were significant predictors of hatching (table 1).

embryos had died within their fertilization envelopes at the four-arm pluteus stage.

\section{Comparisons of Larval Size}

Length was measured in 10 hatched and 10 unhatched embryos from each replicate of trial 3 at $28 \mathrm{~h}$ after fer- tilization (fig. 3A). Hatched embryos were significantly longer than unhatched embryos (mixed-effects ANOVA: $\left.F_{1,18}=81.350, P<.001\right)$. Based on the estimated marginal means for the mixed-effects ANOVA, the average unhatched length was $191.2 \pm 1.3 \mu \mathrm{m}$, while the average hatched length was $207.8 \pm 1.3 \mu \mathrm{m}$. For both hatched and unhatched embryos, length increased significantly as salinity decreased (mixed-effects ANOVA: $F_{2,18}=10.734$, $P=.001)$. Post hoc tests with Bonferroni correction revealed significant differences between embryo length at 26 psu and both 29 psu $(P=.004)$ and 32 psu $(P=.002$; fig. $3 A$ ). There was no significant effect of the interaction between hatching status and salinity on embryo length (mixed-effects ANOVA: $F_{2,18}=2.559, P=.105$ ).

In contrast, hatched embryos were not significantly wider than unhatched embryos at the same age (mixedeffects ANOVA: $F_{1,9}=3.580, P=.091$; fig. $3 B$ ). Based on the estimated marginal means from the mixed-model ANOVA, the average unhatched width was $184.1 \pm 1.9$ $\mu \mathrm{m}$, while the average hatched width was $188.9 \pm 1.9 \mu \mathrm{m}$. There was, however, a significant effect of salinity on embryo width (mixed-effects ANOVA: $F_{2,9}=11.628, P=$ .003; fig. 4). Post hoc tests with Bonferroni correction revealed that embryos at 26 psu were significantly wider than those at $32 \mathrm{psu}(P=.003)$. Embryos at 26 psu were not significantly wider than those at 29 psu $(P=.250)$, nor were embryos at 29 psu significantly wider than those at $32 \mathrm{psu}(P=.057)$. There was no significant effect of the interaction between hatching status and salinity on embryo width (mixed-effects ANOVA: $F_{2,9}=0.063$; $P=.940)$.

\section{Discussion}

Our report describes the first incidence of plasticity in hatching stage in the phylum Echinodermata. A delay in hatching was first observed in clutches from three malefemale pairs of Echinarachnius parma during the summer of 2010. Subsequent examination of an additional three male-female pairs from a different location showed that reduced salinity consistently increased hatching time and resulted in hatching as pluteus larvae rather than as blastulae. These results suggest that delay of hatching may be a common phenomenon in E. parma in response to changes in salinity.

Salinity stress is a common issue in nearshore animals, as salinity can fluctuate greatly in intertidal and shallow subtidal areas (Wheatley 1988). In particular, one of the populations of E. parma used in our study experiences salinities ranging from 21 to 32 psu over the course of the spawning season, suggesting that embryos may commonly experience the degree of salinity reductions tested here (Allen and Pechenik 2010). Previous work on salinity tol- 
Table 1: Logistic regression analysis of the effects of temperature, salinity, and embryo age on hatching success

\begin{tabular}{lrrrrrr}
\hline Predictor & \multicolumn{1}{c}{$\beta$} & SE $\beta$ & Wald's $\chi^{2}$ & df & $P$ & $e^{\beta}$ (odds ratio) \\
\hline Trial 1: & & & & & & \\
$\quad$ Age & 5.934 & .193 & 944.066 & 1 & $<.001$ & 377.554 \\
$\quad$ Temperature & 35.834 & 1.415 & 641.329 & 1 & $<.001$ & $3.653 \times 10^{15}$ \\
Salinity & 2.742 & .110 & 623.978 & 1 & $<.001$ & 15.525 \\
Age $\times$ temp & -2.786 & .097 & 826.927 & 1 & $<.001$ & .062 \\
Age $\times$ salinity & -1.225 & .051 & 587.990 & 1 & $<.001$ & .294 \\
Salinity $\times$ temp & -.219 & .007 & 900.007 & 1 & $<.001$ & .803 \\
Age $\times$ temp $\times$ salinity & .092 & .003 & 693.730 & 1 & $<.001$ & 1.096 \\
Trial 2: & & & & & & \\
Age & 1.313 & .136 & 93.615 & 1 & $<.001$ & 3.718 \\
Salinity & .717 & .074 & 93.140 & 1 & $<.001$ & 2.048 \\
Age $\times$ salinity & -.069 & .005 & 192.116 & 1 & $<.001$ & .933 \\
Trial 3: & & & & & & \\
Age & .216 & .008 & 645.720 & 1 & $<.001$ & 1.241 \\
Salinity & .145 & .014 & 107.985 & 1 & $<.001$ & 1.156 \\
Age $\times$ salinity & -.010 & .001 & $1,041.644$ & 1 & $<.001$ & .990 \\
\hline
\end{tabular}

Note: Trials represent independent male-female pairs.

erance in echinoid larvae has shown that larval survival is reduced when salinity is lowered (Roller and Stickle 1985, 1994) and that larvae will move within the water column to avoid low salinities (Sameoto and Metaxas 2008). Our work complements these previous studies by showing that embryos may reduce exposure to low salinities not only through active swimming but also by delaying hatching.

The trend of a more extreme delay in hatching at lower salinities was present in all trials, but the degree of delayed hatching varied greatly across male-female pairs, suggesting genetic variation in the degree of response to salinity fluctuations. Significant intraspecific variation in reproductive patterns may be a common phenomenon in echinoderms (Turner and Lawrence 1979) and in marine invertebrates more generally (Marshall et al. 2008), but studies of early development frequently examine offspring responses from only a single male-female pair. Similarly, intraspecific variation in larval responses to environmental cues is infrequently investigated but appears to influence rates of larval cloning (Vaughn 2009) and likely other environmental responses as well.

The mechanism by which sand dollars delay hatching is unknown, but we predict that it is related to one or both of two likely mechanisms: (1) heterochronic shifts in production of hatching enzymes and (2) delay in the production and/or function of cilia. Hatching in echinoderms requires embryos to break free of their fertilization envelope through a combination of ciliary beating and chemical degradation by release of a proteolytic hatching enzyme (Lepage and Gache 1990; Mozingo 1993). Hatching-enzyme transcription is under zygotic control, and the hatching-enyzme gene is the first zygotic gene expressed

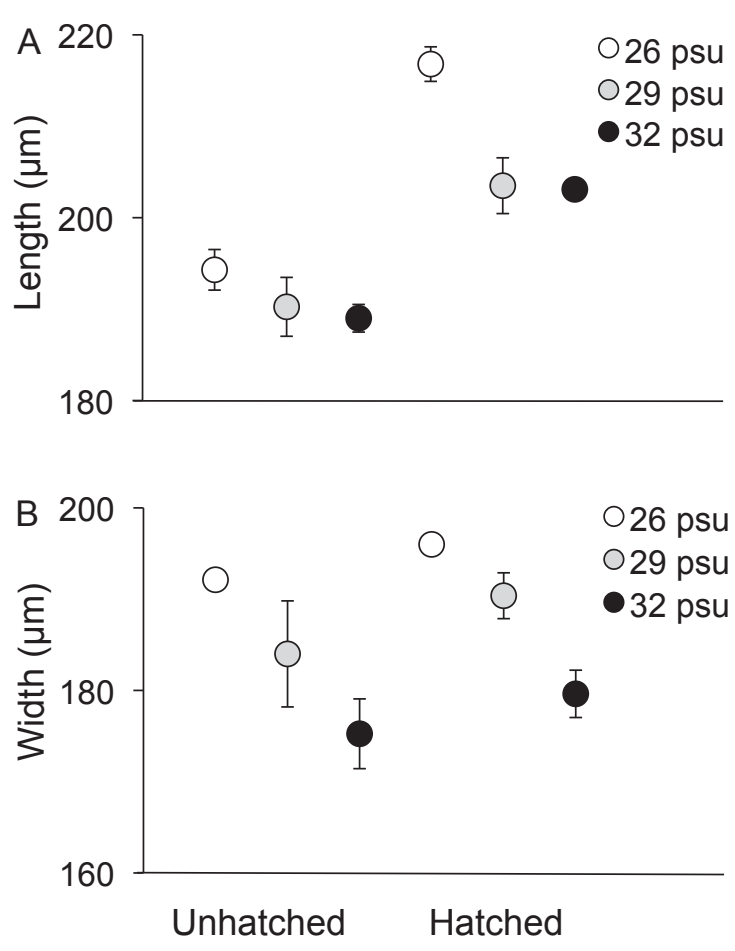

Figure 3: Larval length $(A)$ and width $(B)$ of hatched and unhatched larvae in trial 3. Circles represent mean \pm SE length or width of larvae at $28 \mathrm{~h}$ after fertilization. Larvae at lower salinity were significantly longer and wider than larvae at high salinity. Hatched larvae were significantly longer than but no different in width from unhatched larvae (see "Results" for statistical treatment). 


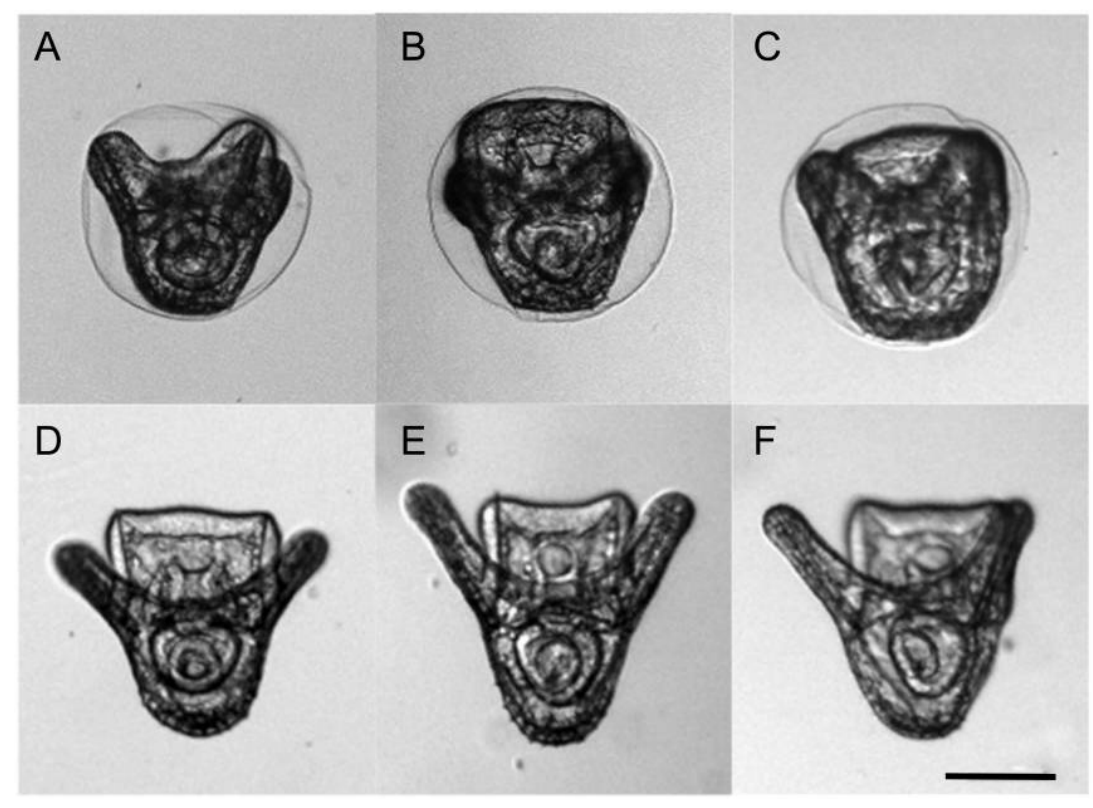

Figure 4: Representative hatched and unhatched larvae of Echinarachnius parma at $37 \mathrm{~h}$ after fertilization. Unhatched larvae from the $32-$ psu $(A), 29$-psu $(B)$, and 26-psu $(C)$ treatments are shown in the top row. Hatched larvae from the 32-psu $(D)$, 29-psu $(E)$, and 26-psu (F) treatments are shown in the bottom row. Scale bar $=100 \mu \mathrm{m}$.

in the sea urchin embryo (Ghiglione et al. 1997). There is a narrow window within which hatching-enzyme transcription occurs. Activation of transcription begins at the eight-cell stage, peaks at the 128 -cell stage, and is completed by the prehatching blastula stage (Lepage and Gache 1990). This suggests that if embryos fail to hatch shortly after this window of expression, then they may not be able to produce more hatching enzyme in later stages. However, it is not known whether hatching enzyme may be stored for later release. Examination of the timing of expression of the gene(s) responsible for producing the hatching enzyme at low salinity would allow a formal test of the hypothesis that heterochronic shifts of enzyme production drive hatching plasticity. Similarly, if the fertilization envelope has been chemically degraded but cilia formation or activity is inhibited, then hatching may not proceed. Rapid increases in salinity (from 30 to $60 \mathrm{psu}$ ) can cause cilia to fall off of echinoderm embryos (Auclair and Siegel 1966). Ciliary activity may also be inhibited in hypotonic seawater, as occurs in bivalve mollusks and ctenophores (Wells et al. 1940). Although the fertilization envelope of echinoderms has limited permeability ( $40 \mathrm{kDa}$; Wong and Wessel 2008), it is permeable to salts in seawater (Harvey 1956), and we have observed significant swelling of the fertilization envelope immediately after immersion in seawater of reduced salinity (J. D. Allen and A F. Armstrong, unpublished data). On the basis of these observations, even embryos that remain within the fertilization envelope may be shielded only temporarily from salinity changes in the external environment. It is, therefore, possible that the delay of hatching that we observed was not an adaptive response but rather a direct physiological consequence of shifts in salinity. However, since cilia are able to regrow after deciliation by salinity shock (Stephens 1995) and since acclimation to salinity changes presumably occurs in the hours before initial cilia growth, salinity-induced reductions in ciliary function may be an unlikely explanation for delay of hatching.

While still intact, the fertilization envelope may protect developing embryos from pathogens or toxins (Wong and Wessel 2008), but is unlikely to provide protection from the planktonic predators that commonly consume eggs and embryos (Vaughn and Allen 2010). It has previously been demonstrated that embryos of marine invertebrates that are unprotected during development have faster cell cycles and shorter times to hatching and swimming (Strathmann et al. 2002). Because swimming by echinoid blastulae is sufficient to move embryos up into the water column (McDonald 2012) and because the water column appears to be a region of relative safety for marine embryos and larvae (Allen and McAlister 2007), early swimming may be the result of natural selection to reduce mortality on marine invertebrate embryos through migration into the plankton (Strathmann 2007). Therefore, staying in the fertilization envelope longer may be adaptive only if outside conditions are sufficiently stressful to outweigh the 
benefits of swimming as a mechanism for negatively buoyant eggs and developmental stages to avoid benthic predators.

The increase in larval length but not width in hatched relative to unhatched larvae suggests that unhatched larvae were not simply slow growers but rather that retention of larvae within the fertilization envelope diminished growth of larval arms (fig. 4). The mechanism for this diminished arm growth appeared to be simple physical obstruction of arm extension. In rare cases, one arm would protrude through the envelope while the other remained within it; in these cases, the protruding arm was much longer than the enclosed one. Since arm length is correlated with ciliary band length and clearance rates in pluteus larvae (Hart 1991; Hart and Strathmann 1994), another cost of delayed hatching may be reduced feeding capacity as early pluteus larvae.

Despite their generally stenohaline distribution, echinoderms must be able to deal with short-term fluctuations in salinity in order to persist in nearshore habitats. Previous work has shown spatial avoidance of low-salinity waters in echinoid larvae (Sameoto and Metaxas 2008), but reduction of low-salinity exposure through delayed hatching has not previously been shown. From the prevalence of sand dollars and other echinoderms in nearshore habitats, delay of hatching could potentially be an adaptive response for avoiding release of embryos into a physiologically stressful environment.

The reunification of the fields of ecology, evolution, and development as "eco-evo-devo" allows biologists an opportunity to provide a more complete view of how development proceeds in natural settings and how variation in the environment affects both individuals and populations (Gilbert 2001; Gilbert and Bolker 2003). The field of eco-evo-devo is especially important for developing predictions of how a changing climate may cause major ecological shifts and/or novel developmental patterns (Sultan 2007). As eco-devo-evo continues to emerge as a discipline, finding appropriate study systems is crucial. It has been proposed that the organisms best suited for eco-evodevo research include those whose development is well documented and who experience significant environmental variation in their natural habitats (Ledon-Rettig and Pfennig 2011). Echinoid echinoderms perfectly fit this description, as they have a long history in developmental biology and, by living near shore (often intertidally), they experience significant environmental fluctuations on a short, developmentally relevant timescale. The environmental stress that echinoderms deal with in the short term by virtue of living in nearshore habitats is often greater than the changes in average environmental conditions that are expected to occur under future climate conditions. Studying developmental responses to environmental stress (e.g., temperature and salinity fluctuations) may be par- ticularly fruitful in echinoderms and other nearshore animals that currently exist in highly variable environments (e.g., California grunion; Matsumoto and Martin 2008), as they may yield insights into the potential of organisms to deal with future extreme environmental conditions. The results of our study not only show an exciting new observation in sand dollar development but also highlight how studying development under different ecologically relevant environmental conditions can yield insights into the biology of even well-studied taxa.

\section{Acknowledgments}

This research was funded by a Suzann Wilson Matthews summer research award from the College of William and Mary to J.D.A. and by grants from the Charles Center at the College of William and Mary to A.F.A. and H.N.B. A.F.A. received travel support from a Howard Hughes Medical Institute grant through the Undergraduate Biological Sciences Education Program to the College of William and Mary and from the Society for Integrative and Comparative Biology (SICB). We thank K. Martin, R. Strathmann, and K. Warkentin for organizing the SICB symposium where this work was first presented. We also thank J. Salyers, D. Schwab, and C. White for laboratory assistance and H. Murphy for statistical advice. Bowdoin College granted us housing and use of their Marine Laboratory during the initial stages of this work. Helpful comments on and discussions of the manuscript were provided by M. Pizer and two anonymous reviewers.

\section{Literature Cited}

Allen, J. D., and J. S. McAlister. 2007. Testing rates of planktonic versus benthic predation in the field. Journal of Experimental Marine Biology and Ecology 347:77-87.

Allen, J. D., and J. A. Pechenik. 2010. Understanding the effects of low salinity on fertilization success and early development in the sand dollar Echinarachnius parma. Biological Bulletin 218:189-199.

Auclair, W., and B. W. Siegel. 1966. Cilia regeneration in the sea urchin embryo: evidence for a pool of ciliary protein. Science 154: 913-915.

Breitburg, D. L. 1990. Near-shore hypoxia in the Chesapeake Bay: patterns and relationships among physical factors. Estuarine, Coastal and Shelf Science 30:593-609.

Gilbert, S. F. 2001. Ecological developmental biology: developmental biology meets the real world. Developmental Biology 233:1-12.

Gilbert, S. F., and J. A. Bolker. 2003. Ecological developmental biology: preface to the symposium. Evolution and Development 5: 3-8.

Ghiglione, C., F. Emily-Fenouil, G. Lhomond, and C. Gache. 1997. Organization of the proximal promoter of the hatching-enzyme gene, the earliest zygotic gene expressed in the sea urchin embryo. European Journal of Biochemistry 250:502-513. 
Hart, M. W. 1991. Particle captures and the method of suspension feeding by echinoderm larvae. Biological Bulletin 180:12-27.

Hart, M. W., and R. R. Strathmann. 1994. Functional consequences of phenotypic plasticity in echinoid larvae. Biological Bulletin 186: 291-299.

Harvey, E. B. 1956. The American Arbacia and other sea urchins. Princeton University Press, Princeton, NJ.

Kaplan, D. M., J. L. Largier, S. Navarrete, R. Guinez, and J. C. Castilla. 2003. Large diurnal temperature fluctuations in the nearshore water column. Estuarine, Coastal and Shelf Science 57:385-398.

Kramer, A. A., and J. E. Zimmerman. 2007. Assessing the calibration of mortality benchmarks in critical care: the Hosmer-Lemeshow test revisited. Critical Care Medicine 35:2052-2056.

Ledon-Rettig, C. C., and D. W. Pfennig. 2011. Emerging model systems in eco-evo-devo: the environmentally responsive spadefoot toad. Evolution and Development 13:391-400.

Lepage, T., and C. Gache. 1990. Early expression of a collagenaselike hatching enzyme gene in the sea urchin embryo. EMBO Journal 9:3003-3012.

Li, D. 2002. Hatching responses of subsocial spitting spiders to predation risk. Proceedings of the Roval Society B: Biological Sciences 269:2155-2161.

Li, D., and R. R. Jackson. 2003. A predator's preference for eggcarrying prey: a novel cost of parental care. Behavioral Ecology and Sociobiology 55:129-136.

. 2005. Influence of diet-related chemical cues from predators on the hatching of egg-carrying spiders. Journal of Chemical Ecology 31:333-342.

Marshall, D. J., R. Bonduriansky, and L. F. Bussière. 2008. Offspring size variation within broods as a bet-hedging strategy in unpredictable environments. Ecology 89:2506-2517.

Martin, K. L. M. 1999. Ready and waiting: delayed hatching and extended incubation of anamniotic vertebrate terrestrial eggs. American Zoologist 39:279-288.

Martin, K. L. M., C. L. Moravek, and A. J. Walker. 2011. Waiting for a sign: extended incubation postpones larval stage in the beach spawning California grunion Leuresthes tenuis (Ayres). Environmental Biology of Fishes 91:63-70.

Matsumoto, J. K., and K. L. M. Martin. 2008. Lethal and sublethal effects of altered sand salinity on embryos of beach-spawning California grunion. Copeia 2008:484-491.

McDonald, K. 2004. Patterns in early embryonic motility: effects of size and environmental temperature on vertical velocities of sinking and swimming echinoid blastulae. Biological Bulletin 207:93102.

- 2012. Earliest ciliary swimming effects vertical transport of planktonic embryos in turbulence and shear flow. Iournal of Experimental Biology 215:141-151.

Mozingo, N. M., L. R. Hollar, and D. E. Chandler. 1993. Degradation of an extracellular matrix: sea urchin hatching enzyme removes cortical granule-derived proteins from the fertilization envelope. Journal of Cell Science 104:929-938.

Oyarzun, F. X., and R. R. Strathmann. 2011. Plasticity of hatching and the duration of planktonic development in marine invertebrates. Integrative and Comparative Biology 51:81-90.

Roller, R. A., and W. B. Stickle. 1985. Effects of salinity on larval tolerance and early developmental rates of four species of echinoderms. Canadian Journal of Zoology 63:1531-1538.

- 1993. Effects of temperature and salinity acclimation of adults on larval survival, physiology, and early development of
Lytechinus variegatus (Echinodermata: Echinoidea). Marine Biology 116:583-591.

. 1994. Effects of adult salinity acclimation on larval survival and early development of Strongylocentrotus droebachiensis and Stronglocentrotus pallidus. Canadian Journal of Zoology 72:19311939.

Sameoto, J. A., and A. Metaxas. 2008. Can salinity-induced mortality explain larval vertical distribution with respect to a halocline? Biological Bulletin 214:329-338.

Sanford, E. 2002. Water temperature, predation, and the neglected role of physiological rate effects in rocky intertidal communities. Integrative and Comparative Biology 42:881-891.

Sih, A., and R. D. Moore. 1993. Delayed hatching of salamander eggs in response to enhanced larval predation risk. American Naturalist 142:947-960.

Staver, J. M., and R. R. Strathmann. 2002. Evolution of fast development of planktonic embryos to early swimming. Biological Bulletin 203:58-69.

Stephens, R. E. 1995. Ciliogenesis in sea urchin embryos: a subroutine in the program of development. BioEssays 17:331-340.

Stickle, W. B., and G. J. Denoux. 1976. Effects of in situ tidal salinity fluctuations on osmotic and ionic composition of body fluid in southeastern Alaska rocky intertidal fauna. Marine Biology 37:125135.

Stickle, W. B., and W. J. Diehl. 1987. Effects of salinity on echinoderms. Pages 235-285 in M. Jangoux and J. M. Lawrence, eds. Echinoderm studies. Vol. 2. Balkema, Rotterdam.

Strathmann, R. R. 1990. Why life histories evolve differently in the sea. American Zoologist 30:197-207.

2007. Three functionally distinct kinds of pelagic development. Bulletin of Marine Science 81:167-179.

Strathmann, R. R., J. M. Staver, and J. R. Hoffman. 2002. Risk and the evolution of cell-cycle durations of embryos. Evolution 56: 708-720.

Sultan, S. E. 2007. Development in context: the timely emergence of eco-devo. Trends in Ecology \& Evolution 22:575-582.

Touchon, J. C., I. Gomez-Mestre, and K. M. Warkentin. 2006. Hatching plasticity in two temperate anurans: responses to a pathogen and predation cues. Canadian Journal of Zoology 84:556-563.

Turner, R. L., and J. M. Lawrence. 1979. Volume and composition of echinoderm eggs: implications for the use of egg size in lifehistory models. Pages 25-40 in S. E. Stancyk, ed. Reproductive ecology of marine invertebrates. University of South Carolina Press, Columbia.

Vaughn, D. 2009. Predator-induced larval cloning in the sand dollar Dendraster excentricus: might mothers matter? Biological Bulletin 217:103-114.

Vaughn, D., and J. D. Allen. 2010. The peril of the plankton. Integrative and Comparative Biology 50:552-570.

Vonesh, J. R., and B. M. Bolker. 2005. Compensatory larval responses shift trade-offs associated with predator-induced hatching plasticity. Ecology 86:1580-1591.

Warkentin, K. M. 1995. Adaptive plasticity in hatching age: a response to predation risk trade-offs. Proceedings of the National Academy of Sciences of the USA 92:3507-3510.

- 2005. How do embryos assess risk? vibrational cues in predator-induced hatching of red-eyed treefrogs. Animal Behaviour 70: $59-71$.

2011. Environmentally cued hatching across taxa: embryos 
respond to risk and opportunity. Integrative and Comparative Biology 51:14-25.

Wells, G. P., I. C. Ledingham, and M. Gregory. 1940. Physiological effects of a hypotonic environment. Journal of Experimental Biology 17:378-385.

Wheatley, M. G. 1988. Integrated responses to salinity fluctuation. American Zoologist 28:65-77.
Wong, J. L., and G. M. Wessel. 2008. Renovation of the egg extracellular matrix at fertilization. International Journal of Developmental Biology 52:545-550.

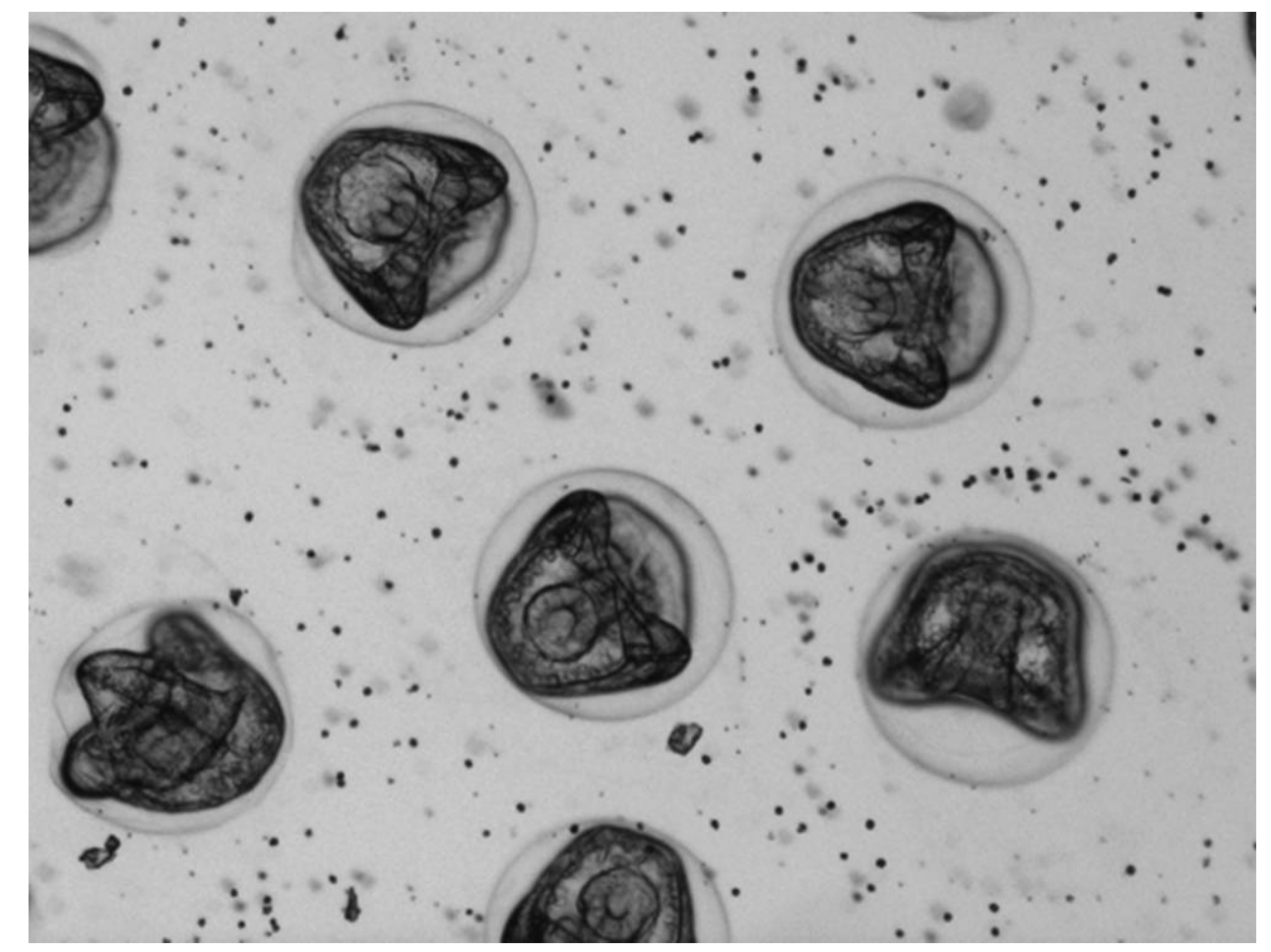

Unhatched larvae of the sand dollar Echinarachnius parma in response to exposure to reduced salinity. Development to the larval stage while still within the fertilization envelope (seen here as fine circles around each embryo) has not previously been reported in any echinoderm species. Photograph by Jonathan D. Allen. 